CLINICAL ETHICS

\title{
Improving the quality of consent to randomised controlled trials by using continuous consent and clinician training in the consent process
}

\author{
P Allmark, S Mason
}

J Med Ethics 2006;32:439-443. doi: 10.1136/jme.2005.013722

See end of article for authors' affiliations

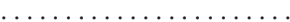

Correspondence to: Dr Peter Allmark, Northern General Hospital University of Sheffield, Samuel Fox House, Herries Road, Sheffield S5 7AU, UK; p.j.allmark@shef.ac. uk

Received 25 July 2005

In revised form

12 October 2005

Accepted for publication

14 October 2005
Objective: To assess whether continuous consent, a process in which information is given to research participants at different stages in a trial, and clinician training in that process were effective when used by clinicians while gaining consent to the Total Body Hypothermia (TOBY) trial. The TOBY trial is a randomised controlled trial (RCT) investigating the use of whole-body cooling for neonates with evidence of perinatal asphyxia. Obtaining valid informed consent for the TOBY trial is difficult, but is a good test of the effectiveness of continuous consent.

Methods: Semistructured interviews were conducted with 30 sets of parents who consented to the TOBY trial and with 10 clinicians who sought it by the continuous consent process. Analysis was focused on the validity of parental consent based on the consent components of competence, information, understanding and voluntariness.

Results: No marked problems with consent validity at the point of signature were observed in 19 of 27 (70\%) couples. Problems were found mainly to lie with the competence and understanding of the parents: mothers, particularly, had problems with competence in the early stages of consent. Problems in understanding were primarily to do with side effects. Problems in both competence and understanding were observed to reduce markedly, particularly for mothers, in the post-signature phase, when further discussion took place. Randomisation was generally understood but unpopular. Information was not always given by clinicians in stages during the short period available before parents gave consent. Most clinicians, however, were able to give follow-up information.

Discussion: Consent validity was found to compare favourably with similar trials examined in the Euricon study.

Conclusion: Adopting the elements of the continuous consent process and clinician training in RCTs should be considered by researchers, particularly when they have concerns about the quality of consent they are likely to obtain by using a conventional process.
T he Total Body Hypothermia Qualitative Substudy (TOBYQUAL study) aimed at evaluating the process of continuous consent used during the TOBY trial funded by the Medical Research Council. The TOBY trial is a randomised controlled trial (RCT; ie, a research study in which patients are allocated at random to receive one of two or more clinical interventions), in which babies born with evidence of perinatal asphyxia are randomised to receive either conventional care or conventional care and whole-body cooling (to $34^{\circ} \mathrm{C}$ ) on a special mattress for $72 \mathrm{~h}$. It presents a challenge for clinicians to obtain valid, informed consent from parents of neonates for at least three reasons: firstly, the trial deals with very sick infants; secondly, the trial treatment needs to be started within $6 \mathrm{~h}$ of birth; and thirdly, treatment is not blind, even to the parents, and yet, babies in the control group not born in specialist treatment centres will need to be transferred to one of these centres. The stress for parents is compounded by the fact that perinatal asphyxial encephalopathy is almost always unexpected. Such circumstances threaten the validity of consent. ${ }^{12}$

The continuous consent approach to obtaining informed consent for RCTs has been proposed as a method for ameliorating this difficulty ${ }^{3}$ by giving parents information at more than one point in the trial so that they will assimilate it better. Such an approach is used in the TOBY trial (http:// www.npeu.ox.ac.uk/toby/index.php), which has three main elements.
- Element 1: If the baby is born in a non-cooling centre, the parents are given preliminary information about the trial, including a preliminary information leaflet, while the baby is assessed for eligibility. (If deemed appropriate, the leaflet may also be given to parents of babies born in a cooling centre, or preliminary information may be offered more informally.)

- Element 2: If the baby is eligible, a second, more comprehensive, information leaflet is given to the parents and further discussion takes place. At this point, parents are asked for their written consent and randomised.

- Element 3: During the intervention period, the consultant neonatologist meets the parents to ensure that they understand the trial procedures and wish to continue participating in the trial. It is made clear that the parents remain free to withdraw their baby from the trial.

The current full information sheet for parents is slightly different from the one that was given to the parents we interviewed. The most important difference is in the section, "How might cooling help?", which has been altered in the light of recent research findings.

Abbreviations: RCT, randomised controlled trial; TOBY-QUAL study, Total Body Hypothermia Qualitative Substudy; TOBY trial, Total Body Hypothermia trial 
In addition, clinicians are given training in obtaining informed consent for the TOBY trial and, at all times, a senior investigator is available to discuss concerns raised by parents during the trial. As the trial took place during the critical initial $72 \mathrm{~h}$ of the neonate's life, the availability of a senior investigator (who was also a senior clinician dealing with the baby's care) was fairly reliable, although there may have been some delay at times (eg, in the middle of the night).

Continuous consent aims at obtaining the best possible informed consent in a situation of urgency. However, has not been evaluated. The objective of the TOBY-QUAL study, the qualitative substudy reported here, was to evaluate the process of continuous consent used in the TOBY trial.

\section{METHODS}

One researcher (PA) conducted semistructured interviews with parents who gave their consent to the TOBY trial and with clinicians who sought it using the above process. The interview questions were open ended and based on the four components of informed consent: competence, information, understanding and voluntariness. ${ }^{4}$ The transcripts were analysed with a well-established, qualitative process (framework analysis). ${ }^{5}$ The validity of consent was assessed against the four components of the consent. A scoring system was used on each component as follows: 1, perfect; 2 , valid: minor problems; 3 , equivocal: major problems; 4 , validity in doubt: serious problems with the standard.

A score was given for each parent both for the point at which they gave formal signed consent and for the point at which they had further discussion with the clinician after the signature but during the treatment phase. These scores were then assimilated and an overall score was given, first for each parent alone and then for the couple together. The interviews were also analysed to discern common themes.

To determine in which category to place the components, the interviews were judged against the criteria for informed consent that have developed across a wide range of ethical and legal literature. For example, the Re. C UK legal judgement gives several criteria by which to judge competence. ${ }^{6}$ Thus, if a mother had received opiates to the extent that she was no longer able to retain fully the necessary information to give informed consent, then this would be deemed either a major or a serious problem (depending on how impaired she was). In a similar way, we would judge parents to have a problem with understanding if, for example, they were unable to give a description of how treatment was randomly assigned. To ensure reliability of analysis, the two investigators analysed each interview independently.

\section{RESULTS}

\section{Background data}

Between January 2003 and July 2004, 55 babies were found to be eligible for the TOBY-QUAL study. Five sets of parents were excluded: one because of poor English and the rest because the consultant asked us not to approach the parents. In all these cases, the baby had died and the consultant felt it inappropriate to approach the parents, for example, because the consultant thought it would be unduly upsetting to talk about the study. The remaining 50 parents were asked to take part in the TOBY-QUAL study: 20 refused or did not respond to the request and 30 were interviewed. Of the parents who were interviewed, the proportion of those whose babies received the trial treatment to the controls was 17:13. In all, 4 of $30(13 \%)$ interviews were with the mother alone, and the rest with both parents. In all but one case, both parents were available to give consent to the TOBY trial. Ten clinicians were interviewed. Table 1 provides demographic information on the parents.

\section{Use of the continuous consent process}

Many parents did not recall the process being used precisely as set out (table 2). The first information sheet was envisioned mainly for use when babies were to be transferred from an outlying hospital; as such, its absence was not considered to be a deviation from the continuous consent process if it was not given in cooling centres. We deemed more important any deviation from elements 2 or 3. Overall, the process was followed fully in 17 cases, mostly in seven, but was not followed in six cases.

\section{Validity of consent}

At the point of signature, the overall consent validity for the couple, taking the best score of either parent, was as follows: 19 of $27(70 \%)$ had a validity score of 1 or 2 (ie, perfect or with minor problems) and 8 of $27(30 \%)$ had a validity score of 3 or 4 (ie, major or serious problems). For three sets of parents, data for the father were missing (eg, where the mother was interviewed alone).

A key finding was the improvement in consent validity at the point of signature to that at the post-signature phase for each parent (table 3). At the point of signature, 22 of 30 $(73 \%)$ mothers and 8 of $27(30 \%)$ fathers had major or serious problems with the validity of their consent. In the post-signature phase (element 3 ), the respective figures were 7 of $29(24 \%)$ and 4 of 26 (15\%; data missing from four sets of parents). Thus, there was a general improvement seen in both mothers and fathers from element 2 to element 3 of the consent process. This was more marked for mothers, perhaps

Table 1 Social class, ethnicity and age of parents giving informed consent to the Total Body Hypothermia trial

\begin{tabular}{|c|c|c|c|c|c|c|c|}
\hline \multirow{2}{*}{ Social class* } & \multirow{2}{*}{$\begin{array}{l}\text { Number of } \\
\text { parents }\end{array}$} & \multicolumn{3}{|l|}{ Ethnicity† } & \multicolumn{3}{|l|}{ Age (years) } \\
\hline & & & Mother & Father & & Mother & Father \\
\hline 1: Higher managerial and professional & al 1 & White, UK & 24 & 19 & $16-19$ & 1 & 0 \\
\hline 2: Lower managerial and professional & 18 & White, other & 2 & 6 & $20-29$ & 9 & 5 \\
\hline 3: Intermediate occupations & 3 & Pakistani & 1 & 1 & $30-39$ & 18 & 17 \\
\hline $\begin{array}{l}\text { 4: Small employers and own account } \\
\text { workers }\end{array}$ & 2 & Black, Caribbean & 1 & 0 & $>40$ & 1 & 5 \\
\hline 5: Lower supervisory and technical & 5 & Black, African & 2 & 3 & Not known & 1 & 3 \\
\hline 6: Semiroutine occupations & 2 & Not known & 0 & 1 & Total number & 30 & 30 \\
\hline 7: Routine occupations & 5 & Total number & 30 & 30 & & & \\
\hline $\begin{array}{l}\text { 8: Never worked/long-term } \\
\text { unemployed }\end{array}$ & 3 & & & & & & \\
\hline Not known & 1 & & & & & & \\
\hline Total number & 30 & & & & & & \\
\hline
\end{tabular}

*Based on Office of National Statistics Classification (www.statistics.gov.uk; accessed 30 May 2005).

†Based on Office of National Statistics Classification (www.statistics.gov.uk; accessed 30 May 2005). Ethnic groups not represented were mixed, Indian, Bangladeshi, other Asian, other Black, Chinese and other ethnic. 


\begin{tabular}{|c|c|}
\hline \multicolumn{2}{|l|}{ Element 1} \\
\hline First sheet given separately (transferral centre) & 5 \\
\hline First sheet given separately (cooling centre) & 3 \\
\hline First sheet given with main information sheet & 12 \\
\hline $\begin{array}{l}\text { (cooling and transter centres) } \\
\text { First information sheet not remembered being } \\
\text { given (transferral centre) }\end{array}$ & 3 \\
\hline $\begin{array}{l}\text { First information sheet not remembered being } \\
\text { given (cooling centre) } \\
\text { Flement } 2\end{array}$ & 7 \\
\hline Main information sheet given with discussion & 26 \\
\hline Main information sheet given after signed consent & 1 \\
\hline $\begin{array}{l}\text { Main information sheet not remembered being } \\
\text { given, but discussion took place } \\
\text { Element } 3\end{array}$ & 3 \\
\hline \multicolumn{2}{|l|}{ Element 3} \\
\hline No follow-up discussion remembered (baby died) & $\begin{array}{l}3 \text { (all in control } \\
\text { group) }\end{array}$ \\
\hline No follow-up discussion remembered (baby lived) & $\begin{array}{l}3 \text { ( } 2 \text { in control } \\
\text { group) }\end{array}$ \\
\hline
\end{tabular}

because they had the greater problem in the first place: 19 of $29(66 \%)$ mothers showed an improvement as against 9 of 26 (35\%) fathers. Table 3 shows each consent component in more detail.

\section{Competence}

A total of 18 of $30(60 \%)$ mothers had impaired competence (scored 3 or 4 ) at the point of signature (table 4). This was largely due to the anaesthesia, opiates and other problems associated with a traumatic birth.

I just, I really can't remember anything at the time; ... I was smacking myself on the nose to keep myself awake because I was just like this [gestures sleepy] my head was spinning; most of the day is a blur anyway, most of the labour's a blur ... they give you morphine .... [Mother: 24] (The interview number at the end of each quote shows the variety of sources used.)

Fathers, however, were able to compensate; all but one father (whose first language was not English) scored 1 or 2 for competence at the point of signature. None the less, some fathers did find consent difficult owing to factors such as the speed and suddenness of events combined with the emotional trauma. In cases where fathers were more competent at the time of signature, they usually signed the consent form. On a few occasions, less competent mothers were asked to sign because the couple was not married. One unmarried father signed on behalf of his incompetent partner. The competence of the mothers generally improved in the post-signature phase and they were usually able to play an active part in the third element of the continuous consent process.

\section{Information}

The main problem in the pre-signature phase was that 4 of 30 $(13 \%)$ sets of parents did not recall receiving a main information sheet. In the post-signature phase, 6 of 30 $(20 \%)$ did not recall receiving follow-up information (table 4 ), although in half of these cases the baby died (and, therefore, follow-up information would have been inappropriate).

\section{Understanding}

At the point of signature, 19 of $30(63 \%)$ mothers and 7 of 27 (26\%) fathers had poor understanding (scored 3 or 4 ; table 4 ). In the post-signature phase, there was a marked improvement:
Table 3 Consent validity at the point of signature and post signature for each parent, and improvement of validity post signature

\begin{tabular}{|c|c|c|c|c|}
\hline \multirow[b]{2}{*}{ Validity score } & \multicolumn{2}{|c|}{ Mother } & \multicolumn{2}{|c|}{ Father } \\
\hline & A & $\mathbf{P}$ & A & $\mathbf{P}$ \\
\hline 1, Perfect & 0 & 8 & 3 & 9 \\
\hline 2, Minor problems & 8 & 14 & 16 & 13 \\
\hline 3, Major problems & 12 & 3 & 5 & 2 \\
\hline 4, Serious problems & 10 & 4 & 3 & 2 \\
\hline Don't know & 0 & 1 & 3 & 4 \\
\hline Total number & 30 & 30 & 30 & 30 \\
\hline $\begin{array}{l}\text { Improved post } \\
\text { signature }\end{array}$ & 19 & & 9 & \\
\hline $\begin{array}{l}\text { Stayed the same } \\
\text { post signature }\end{array}$ & 10 & & 17 & \\
\hline No information & 1 & & 4 & \\
\hline Total number & 30 & & 30 & \\
\hline
\end{tabular}

the respective figures were 10 of $29(34 \%)$ and 5 of 26 (19\%). The problems of understanding for the mothers seemed to result largely from their competence problems; however, a number of themes emerged across the range of parents.

\section{Treatment}

After element 3 of the consent process, almost all parents grasped the general idea of whole-body hypothermia, the procedure and its basic rationale. The main reason parents gave for their consent was the hope that trial entry would improve their baby's prospects. One or two parents also hoped that the trial would contribute to future knowledge.

\section{Side effects}

The main information sheet of the TOBY trial says the following:

... there is a possibility that cooling may lead to problems with blood pressure control, abnormal heart rhythm, bleeding and clotting problems and chemical and sugar imbalances in the blood.

Some clinicians highlighted this point, whereas others said they played down the side effects. Table 5 summarises parental awareness of side effects. Surprisingly, despite being given the main information sheet (and usually being orally informed about side effects), as many as $48 \%$ of the parents who were interviewed did not seem to have knowledge of the side effects at interview. In all, 6 of $30(11 \%)$ parents did not recall being informed of side effects (eg, some said they were explicitly told that there were none, others did not recall being given the main information sheet). Some parents said that they gave consent only because they believed that the treatment would not harm the baby.

Our main concern was whether it would have side effects, that was our main concern; any side effects and we wouldn't have given our consent. [Father: 11]

For other parents, the situation may have seemed so severe that side effects were of little importance to them.

We fully understood what he wanted to do in terms of treatment ... we fully understood the side effects if there was going to be any, or the risks involved, but obviously whatever anyone tells you all you listen to is that your child is damaged ... [Mother: 2] 
Table 4 Validity of individual components at the point of signature and post signature for each parent

\begin{tabular}{|c|c|c|c|c|c|c|c|c|c|c|c|c|c|c|c|c|}
\hline \multirow[b]{3}{*}{ Validity score } & \multicolumn{4}{|c|}{ Competence } & \multicolumn{4}{|c|}{ Information } & \multicolumn{4}{|c|}{ Understanding } & \multicolumn{4}{|c|}{ Voluntariness } \\
\hline & \multicolumn{2}{|c|}{ Mother } & \multicolumn{2}{|c|}{ Father } & \multicolumn{2}{|c|}{ Mother } & \multicolumn{2}{|c|}{ Father } & \multicolumn{2}{|c|}{ Mother } & \multicolumn{2}{|c|}{ Father } & \multicolumn{2}{|c|}{ Mother } & \multicolumn{2}{|c|}{ Father } \\
\hline & A & $\mathbf{P}$ & A & $\mathbf{P}$ & A & $\mathbf{P}$ & A & $\mathbf{P}$ & A & $\mathbf{P}$ & A & $\mathbf{P}$ & A & $\mathbf{P}$ & A & $\mathbf{P}$ \\
\hline 1, Perfect & 3 & 24 & 13 & 22 & 20 & 23 & 21 & 23 & 1 & 8 & 5 & 8 & 23 & 27 & 22 & 25 \\
\hline 2, Minor problems & 9 & 3 & 12 & 2 & 4 & 1 & 3 & 0 & 10 & 11 & 15 & 13 & 6 & 2 & 4 & 1 \\
\hline 3, Major problems & 10 & 2 & 1 & 1 & 3 & 2 & 1 & 1 & 9 & 6 & 4 & 3 & 0 & 0 & 1 & 1 \\
\hline 4, Serious problems & 8 & 0 & 0 & 0 & 3 & 3 & 2 & 2 & 10 & 4 & 3 & 2 & 1 & 1 & 0 & 0 \\
\hline Don't know & 0 & 1 & 4 & 5 & 0 & 1 & 3 & 4 & 0 & 1 & 3 & 4 & 0 & 0 & 3 & 3 \\
\hline Total number & 30 & 30 & 30 & 30 & 30 & 30 & 30 & 30 & 30 & 30 & 30 & 30 & 30 & 30 & 30 & 30 \\
\hline
\end{tabular}

\section{Randomisation}

In 3 of $30(10 \%)$ interviews, it seemed that the parents had not grasped the fact that treatment would be chosen randomly. For example, one parent thought that randomisation was used to allocate a scarce resource. In the remaining interviews, at least one parent in each couple had a reasonable understanding of randomisation. Many parents, however, disliked the method. Generally, those who received control were disappointed, whereas those who received cooling were relieved.

I remember saying to him, "Oh great, great, like some effing placebo" is what I said to him; so, no, I totally understood that idea, so I was kind of glad [because the baby received cooling]. [Mother: 4]

\section{Voluntariness}

Clinicians showed concern about the voluntariness of parents' consent (table 4):

.... it's easy for someone to put a gun to your head and say it's your decision. And the gun being that their baby is born and is damaged and is needing a lot of resuscitation and here we are saying, look there's a trial happening and this is the only thing available, and there's nothing else available ... [Clinician: 6]

And this was certainly something many parents spoke about:

\section{Interviewer: What made you say yes?}

Father: Desperation, I suppose, there was no other option and it was worth a shot, and that is the truth. [Father: 15]

None the less, only two parents had a major or serious problem related to voluntariness; most parents were clear that the decision was theirs, that normal treatment was available outside the trial and that they could withdraw.

Table 5 Parental recall of side effects of total-body cooling (55 parents of 30 babies)

\begin{tabular}{ll}
\hline & $\mathbf{n}(\%)$ \\
\hline $\begin{array}{l}\text { Aware of side effects before signing consent form } \\
\text { Aware of side effects after signing consent form }\end{array}$ & $19(34)$ \\
$\begin{array}{l}\text { Side effects not acknowledged, although clearly informed } \\
\text { about them (eg, had read main information sheet) }\end{array}$ & $18(3)$ \\
$\begin{array}{l}\text { Not aware of side effects, although given main } \\
\text { information sheet (but this had not been read) }\end{array}$ & $8(15)$ \\
$\begin{array}{l}\text { Not properly informed of side effects } \\
\text { Total number }\end{array}$ & $6(11)$ \\
\hline
\end{tabular}

Some parents mentioned this withdrawal option as a reason for giving their consent in the first place. Thus, voluntariness seems to have been achieved at the point of signature despite the short period available and the desperation of the parents.

\section{Attitudes to the consent process}

Twenty-six (96\%) sets of parents said that they thought it was right that clinicians sought their consent for the trial (data from three sets of parents are missing). Some parents talked of their right to decide on behalf of their child. Other parents said that being asked for consent enabled them to feel that they were participating in their child's care, perhaps for the first time. Clinicians also generally viewed consent as valuable or necessary. But, at least two pointed to the scientific cost associated with delaying randomisation and trial entry while obtaining consent.

Only two parents noted problems with the use of continuous consent itself. Both problems were related to receiving additional information at a later stage. For example, one father said,

We were told a hell of a lot more on the [element 3 stage] than we were on the [element 2, day of birth]. [Father: 10]

\section{DISCUSSION}

Interpretation of our study requires a discussion on its limitations. Firstly, we relied on the memory of participants, which may be flawed. ${ }^{7}$ This problem applies to any interviewbased study on a phenomenon and is obviated in our study by the fact that 12 of $30(40 \%)$ interviews were conducted within 1 month of the baby's birth, and 22 of 30 (73\%) within 3 months; all were conducted within 12 months. Furthermore, flawed memory should, if anything, worsen the results, because parents, for example, lose their understanding of randomisation. Therefore, flawed memory does not undermine our generally positive findings on continuous consent.

Perhaps it may be argued that interviewees were inclined to give a positive assessment of the consent process as the immediate memory faded, particularly in the presence of a kindly interviewer; a type of Hawthorne effect. Three points, however, make this unlikely. Firstly, many of our questions probed objective measures, such as knowledge of randomisation; a kindly interviewer cannot create this knowledge. Secondly, parents were willing to criticise elements of the consent process, particularly randomisation. Thirdly, it would be odd for a Hawthorne effect to be present in the TOBYQUAL study that was not present in the many other studies of consent to RCTs, which found consent of poorer quality.

Another limitation relates to our sample. Twenty sets of parents either declined or did not respond to our request for an interview. A higher proportion of deaths was recorded in the non-respondent group ( $40 \% v 13 \%$ ). We should, however, bear in mind that many of the babies who survived were 
impaired to varying degrees. Their parents would not necessarily have a particularly rosy view of the TOBY trial compared with those whose babies died. Another issue is that we interviewed only those parents who gave consent to the TOBY trial; some parents had refused it. Our reason for excluding this group is that they did not go through the continuous consent process and, therefore, could not comment on it.

The chief aim of the TOBY-QUAL study was to judge whether the standardised, continuous consent process used in the TOBY trial was successful at obtaining valid informed consent from parents. The time available for consent is short and research is looking at a treatment for a life-threatening condition in the neonate. The Euricon Study ${ }^{1}$ interviewed 30 sets of parents who had given consent to similar studies. In the Euricon Study, at the point of signature, there were major or serious problems with consent validity in at least 17 of 30 $(57 \%)$ cases. (This is the lowest possible estimate; it may have been higher.) The equivalent figure in the TOBY trial is 8 of $27(30 \%)$ parents: this is a marked improvement on the Euricon figures and suggests that clinicians in the TOBY trial, by using the continuous consent process, had done well in difficult circumstances. Perhaps more importantly, in the post-signature phase (element 3 ), the validity scores often improved, particularly for mothers. This is one of the successes of continuous consent. With conventional consent procedures, mothers whose competence is impaired up to the point of signature can be sidelined from consent; with continuous consent, they are not.

What explains this relative success? In the first place, clinicians in the TOBY trial were offered training and support in the process of obtaining consent (including role play and workshops). The success in obtaining a relatively good quality of consent at the point of signature is presumably partly due to this training and partly due to element 1 (formal or informal) and element 2. The improvement in the post-signature phase shows the benefit of the formal followup discussion (element 3) and, presumably again, the training of clinicians.

This has implications for other trials. Numerous empirical studies have uncovered a poor standard of informed consent to RCTs. ${ }^{8-10}$ It is tempting to conclude that valid informed consent cannot be obtained, particularly in difficult situations. ${ }^{11}$ The TOBY trial shows that careful attention to consent can, at least to some extent, overcome the difficulties. Researchers should consider using aspects of the continuous consent process, particularly where they believe that obtaining valid informed consent may be difficult.

One such aspect is the formal training of researchers in obtaining informed consent. Presently, clinicians have little, if any, such training. ${ }^{3}$ This may change as ethics and communication enter medical curricula. The training for clinicians in the TOBY trial, however, is geared specifically at gaining informed consent for that trial; such an approach may be more helpful than a generic one.

A second aspect is treating informed consent as a process rather than as a point (ie, the point where a signature is given). This recommendation has been made before. ${ }^{12}$ In the TOBY trial, it is done through graded information (element 1 , followed by element 2) before signed consent and formal follow-up discussion (element 3). We found element 3 to be most helpful to mothers who are unwell after the birth. As such, it may be of particular use in cases where consent is obtained from people with acute illnesses. Many of the fathers, however, also seemed to benefit from the follow-up; hence, its use should not necessarily be restricted to those who are acutely ill. Element 1 may be particularly helpful in non-urgent situations in which there is a lot of complex information to convey.

Another factor researchers can take from the TOBY trial is the attitude to informed consent. The decision to use continuous consent showed that the trial investigators viewed consent as important, much attention was paid to the design of the process and clinicians were trained in its use. Some of the positive findings from this study, such as the overwhelming voluntariness of parental consent, may reflect the attitude of the clinicians to consent as much as the process itself. Overall, the TOBY-QUAL study suggests that a process view of consent, reflected in a design such as continuous consent, can help clinicians obtain valid informed consent.

\section{ACKNOWLEDGEMENTS}

We acknowledge the help of the investigators of the TOBY trial, Brenda Strohm (the TOBY trial coordinator) and the parents and clinicians who shared their views with us.

\section{Authors' affiliations}

P Allmark, Northern General Hospital, University of Sheffield, Sheffield, UK

S Mason, Clinical Trials Research Unit, University of Leeds, Leeds, UK

Funding: This study was sponsored by the Medical Research Council, UK.

Competing interests: None.

Role of funding source: The Medical Research Council funded the Total Body Hypothermia Qualitative Substudy, but had no role, other than as referee, in the study design or in the collection, analysis and interpretation of data.

Ethical approval: North West Multi-centre Research Ethics Committee (UK) granted approval for this study on 27 March 2003 (number MREC 03/8/9). All necessary LRECs and Trust Research and Development Departments approved the study.

Contributors: PA conducted and transcribed the interviews; participated in the design of the study, analysis of data and writing of the final report. SM was chief investigator for the study; she participated in the design of the study, analysis of data and writing of the final report.

\section{REFERENCES}

1 Mason SA, Allmark PJ. Obtaining informed consent to neonatal randomised controlled trials: interviews with parents and clinicians in the Euricon study. Lancet 2000;356:2045-51.

2 Snowdon C, Garcia J, Elbourne D. Making sense of randomization: responses of parents of critically ill babies to random allocation of treatment in a clinical trial. Soc Sci Med 1997;45:1337-55.

3 Euricon partnership. Consensus statement. In: Mason S, Megone C, eds. European neonatal research consent, ethics committees and law. Ashgate: Aldershot, 2001:261-72.

4 Beauchamp T, Childress J. Principles of biomedical ethics, 5th edn. Oxford: Oxford University Press, 2001.

5 Ritchie J, Spencer L. Qualitative data analysis for applied policy research. In: Bryman A, Burgess R, eds. Analyzing qualitative data. London: Routledge, 1994:173-94.

6 Re. C. Adult: refusal of medical treatment 1994, 1 WLR 290

7 Snowdon C, Garcia J, Elbourne D, et al. Trial experience and problems of parental recollection of consent [letter]. BMJ 2001;322:49.

8 Edwards S, Lilford R, Braunholtz D, et al. Ethical issues in the design and conduct of randomised controlled trials. Health Technol Assess 1998;2.

9 Sugarman J, McCrory D, Powell D, et al. Empirical research on informed consent: an annotated bibliography. Hastings Cent Rep, 1999;29 (Special supplement)..

10 Kodish E, Eder $M$, Noll R, et al. Communication of randomization in childhood leukaemia trials. JAMA 2004;291:470-5.

11 Silverman W. The myth of informed consent: in daily practice and in clinical trials. J Med Ethics 1989;15:6-11.

12 American College of Physicians. Ethics manual. Ann Intern Med 1998; 128:576-94. 